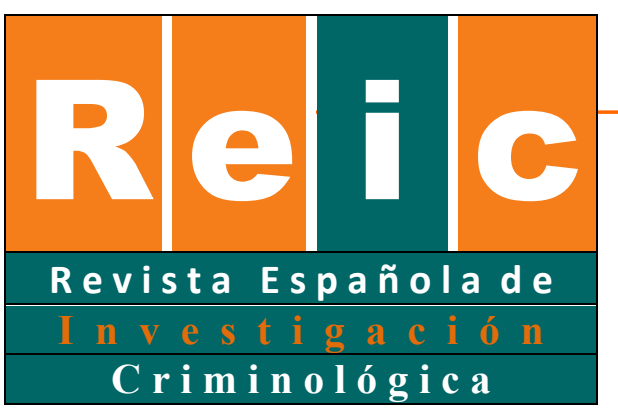

Pereda, Gómez-Martín, Greco, Hombrado \& Segura

\title{
¿Qué factores inciden para romper el silencio de las víctimas de abuso sexual?
}

Which factors encourage sexual abuse victims to break the silence?

Noemí Pereda (iD), Ana M. Greco (D), Jaume Hombrado (iD y Anna Segura ${ }^{1}$ (DD Grupo de investigación en Victimización Infantil y Adolescente (GReVIA) Universitat de Barcelona

Víctor Gómez-Martín (DD

Universitat de Barcelona

\section{RESUMEN}

El objetivo de este estudio es incrementar el conocimiento sobre el proceso de revelación y denuncia del abuso sexual infantil en España, mediante entrevistas a 15 víctimas adultas que han vivido esta experiencia antes de los 18 años. Se han recogido datos sobre la revelación y denuncia, la reacción de sus interlocutores y su opinión respecto de la prescripción de estos delitos. La mayoría revelaron el abuso tanto en la infancia como en la adultez, pero sólo sintieron que les resultaron de ayuda las revelaciones hechas en esta última etapa. Un caso se denunció en la infancia y dos durante la adultez, habiendo transcurrido cerca de veinte años desde la edad de inicio de los abusos. Las víctimas que denunciaron reportan sentirse satisfechas con la decisión, aunque han definido el proceso como duro. La totalidad de la muestra opina que los delitos sexuales contra menores no deberían prescribir.

Palabras clave: víctima, prescripción, delitos contra la libertad sexual, infancia, España.

\footnotetext{
${ }^{1}$ La correspondencia debe dirigirse a: Noemí Pereda, Facultad de Psicología, Universitat de Barcelona, Passeig Vall d'Hebron, 171, 08035 Barcelona. Correo electrónico: npereda@ub.edu
}

Revista Española de Investigación Criminológica

Artículo 12, Número 16 (2018)

https://doi.org/10.46381/reic.v16i0.195

www.criminologia.net

ISSN: 1696-9219 


\begin{abstract}
The main aim of this study is to enlarge the knowledge about the procedure of disclosure and reporting of child sexual abuse, based on victim's answers. In order to achieve this, 15 adults who suffered sexual abuse before their 18 birthday were interviewed. Data was gathered about their disclosure and reporting experiences in childhood and in adulthood, the reactions around them and their opinion about the legal limits for this type of felony. Most victims disclosured the abuse in childhood and as grown-ups, although only during the latter period they found this helpful. Only one case had reported during childhood and two have done it when adults, nearly twenty years after the age of onset. Victims felt satisfied with the decision of reporting, even though they described the process as hard. All participants thought that sexual felonies against children should not prescript.
\end{abstract}

Keywords: victim, prescription, sexual crimes, childhood, Spain.

\title{
1. Introducción
}

El abuso sexual infantil es un problema con graves repercusiones para el desarrollo de sus víctimas, que afecta a un porcentaje importante de la población de menores en España (8.8\% en Pereda, Abad, \& Guilera, 2016). Estas cifras se incrementan si preguntamos a adultos sobre sus experiencias de abuso sexual en la infancia (14.6\% en Benavente, Casado, Orte, \& Ballester, 2016; 17,9\% en Pereda \& Forns, 2007), mostrando que la revelación de los abusos no es inmediata y que, en muchos casos, requiere de un proceso de reflexión y de recuperación emocional (Tamarit, Abad, \& Hernández-Hidalgo, 2015).

El abuso sexual infantil se caracteriza por el secretismo que envuelve la relación entre víctima y victimario, y el silencio que la acompaña. Entre los motivos para no revelar esta experiencia se han identificado factores personales, relacionados con la propia víctima y la dinámica establecida con el abusador, y factores vinculados a la reacción social frente a la experiencia de abuso sexual (Palmer, Brown, Rae-Grant, \& Loughlin, 1999), entre los cuales destaca la respuesta de los profesionales implicados en el proceso de denuncia (Lievore, 2003). Las víctimas que han comunicado los abusos en la edad adulta, o no lo han hecho nunca, se caracterizan también por determinadas dinámicas familiares como la rigidez en las relaciones entre los miembros, estereotipos en la forma de comportarse en función del sexo,

Revista Española de Investigación Criminológica

Artículo 12, Número 16 (2018)

https://doi.org/10.46381/reic.v16i0.195

www.criminologia.net

ISSN: 1696-9219 
la presencia de otras formas de violencia, escasa comunicación y el aislamiento social (Alaggia \& Kirshenbaum, 2005). Otras razones para no denunciar son los vínculos familiares con el abusador, la represión de los recuerdos o un estado de confusión respecto al abuso, no estar emocionalmente preparado para la denuncia, no haber revelado el abuso a la familia, desconfianza hacia el sistema de justicia y factores relacionados con las pocas expectativas de éxito (Tamarit et al., 2015). De esta forma, la revelación resulta ser un proceso complejo, más que un hecho aislado, en el que las actitudes familiares, sociales y culturales juegan un papel relevante (Alaggia, 2010).

Pero la revelación del abuso sexual, tal y como se ha constatado en estudios previos (Smyth, Pennebaker, \& Arigo, 2012), es fundamental para su superación. Se trata de una variable que modula las percepciones y sentimientos de la víctima, influyendo en el tipo, intensidad y evolución de la sintomatología que suele desarrollar (Ullman, 2002). La revelación del suceso y la expresión de las emociones protege la salud física y mental del individuo frente a una experiencia traumática (Smyth et al., 2012) y no revelarlo aumenta el riesgo de consecuencias negativas a largo plazo. A nivel terapéutico, recordar y verbalizar el suceso, enfrentarlo en un ambiente de seguridad y apoyo, ayuda a transformar las imágenes fragmentadas y caóticas del trauma, mantenidas en la memoria emocional, en recuerdos ordenados en la memoria verbal. La víctima necesita describir la experiencia de abuso y los sentimientos asociados para reformular las distorsiones vinculadas a ella misma (sentimiento de culpa, autoconcepto negativo), a los demás (desconfianza generalizada) y al futuro (desesperanza). Ha de dejar atrás la victimización (Baca, 2003) y resignificar la experiencia para darle un nuevo lugar en su identidad y vida actuales. Para ello, en muchos casos, revelar e interponer una denuncia es el inicio de una nueva vida.

La no revelación durante la infancia supone que muchos niños y niñas sigan sufriendo esta forma de victimización durante años, que no reciban la ayuda ni los recursos que necesitarían para superarla y evitar el desarrollo de graves problemas en múltiples áreas de la vida. Sin embargo, esta revelación no se produce, en la mayoría de casos, hasta que las víctimas no alcanzan la adultez (Ahrens, Stansell, \& Jennings, 2010; Tener \& Murphy, 2015), tardándose entre 3 y 18 años desde que se produce el abuso (Alaggia, 2010). Esto genera una

\section{Revista Española de Investigación Criminológica}

Artículo 12, Número 16 (2018)

https://doi.org/10.46381/reic.v16i0.195

www.criminologia.net

ISSN: 1696-9219 
importante duda y desconfianza en el entorno de la víctima, tanto informal, por parte de familiares y amigos, como en los recursos formales profesionales. Así, la víctima suele sentirse desacreditada una vez decide notificar los hechos a las autoridades.

Según estudios españoles, sólo el 9.3\% de los adolescentes víctimas de abuso sexual reporta los abusos a la policía o a los juzgados (Pereda et al., 2016). Estos datos son consistentes con estudios anteriores que mostraron que el 90\% de los abusos sexuales contra menores no se reportaron a las autoridades durante la infancia de las víctimas (López, 1994). Estos resultados se asemejan a los obtenidos por trabajos con muestras europeas (e.g., Priebe \& Svedin, 2008) y con la revisión internacional de Ullman (2002), que constata que una gran parte de las víctimas no llegará a explicar los abusos a nadie a lo largo de su vida.

Un factor personal muy relevante para la no revelación durante la infancia parece ser la disociación que presentan como mecanismo de defensa muchas de estas víctimas (Tener \& Murphy, 2015) y que les permite mantener las emociones vinculadas con la experiencia alejadas de su vida cotidiana y seguir adaptadas a la realidad, como si los abusos no estuvieran sucediendo (Spiegel et al., 2011). Esto puede llevar a reprimir los recuerdos durante largos períodos de tiempo e, incluso, generar dudas sobre la veracidad de lo acontecido (Fisher, Daigle, Cullen, \& Turner, 2003), lo cual podría explicar las diferencias entre los porcentajes de abuso sexual encontrados al preguntar a víctimas menores de edad y los obtenidos al entrevistar a víctimas adultas (Pereda, 2016).

También las respuestas negativas que con frecuencia deben afrontar las víctimas de abuso sexual conducen a una perpetuación del secretismo y del silencio (Draucker et al., 2011). Estas reacciones negativas y culpabilizadoras por parte del entorno de la víctima frente a la revelación del abuso son frecuentes, especialmente en víctimas de sexo masculino (Sorsoli, Kia-Keating, \& Grossman, 2008), en casos de abuso sexual infantil intrafamiliar y por parte de familiares de sexo masculino (Stroud, 1999), así como por las fuentes del denominado apoyo formal (e.g., policía, profesionales del ámbito médico) (Ullman, 1999).

En este contexto debe considerarse la prescripción del delito. De acuerdo con el Código Penal español (art. $131 \mathrm{CP}$ ), los delitos contra la libertad sexual con víctimas menores prescriben, según el caso, a los 10 o 15 años de su comisión. En estos supuestos, cuando la

Revista Española de Investigación Criminológica

Artículo 12, Número 16 (2018)

https://doi.org/10.46381/reic.v16i0.195

www.criminologia.net

ISSN: 1696-9219 
víctima decide denunciar, el hecho delictivo en muchos casos ya ha prescrito. Ello obliga a plantearse posibles soluciones normativas. Tres son las más habituales en Derecho comparado: a) incrementar las penas de los delitos con víctimas menores, con la consiguiente ampliación del plazo de prescripción (Italia); b) establecer una regla específica de prescripción para estos casos, consistente, por lo general, en suspender el cómputo hasta que la víctima menor cumpla una determinada edad (España); y c) declarar la imprescriptibilidad de los delitos sexuales con víctimas menores de edad (Estados Unidos).

De las tres alternativas expuestas, la b) es la que mejor equilibra la balanza en términos de la gravedad del hecho y la respuesta penal correspondiente. No obstante, suspender la prescripción del delito hasta que la víctima haya cumplido los 18 años, como dispone el Código penal español, probablemente no represente la mejor de las soluciones. Considerando la complejidad de revelar un abuso sexual para la mayoría de las víctimas (Alaggia, 2010), las franjas de edad con las que operan los Códigos penales de Suiza (25), Austria (28) o Alemania (30 años) podrían adaptarse mejor a las barreras que suelen dificultar la denuncia. Sin embargo, en ocasiones, estas barreras se prolongan más allá de los 30 años. Convendría, por ello, que la redacción de las cláusulas de suspensión de la prescripción se adaptase de modo más concreto a la fenomenología del problema. Para conseguirlo, la regla de extensión de la prescripción no tendría que consistir en la suspensión de la prescripción del delito hasta que la víctima llegue a una edad concreta, sino hasta que se rehaga del bloqueo psicológico o supere la vinculación material, emocional o económica con el agresor que le impide denunciarlo (Gómez Martin, 2016).

\section{Objetivos del estudio}

La investigación que se presenta pretende aportar conocimiento actualizado y específico para ayudar a contribuir al desarrollo de medidas político-criminales y judiciales que favorezcan unas condiciones adecuadas para la revelación de abusos sexuales. Asimismo, el estudio permite acercarse a las posibles razones por las cuales la víctima no denuncia los hechos, para aportar información relevante al debate actual sobre cuál ha de ser la orientación de las

Revista Española de Investigación Criminológica

Artículo 12, Número 16 (2018)

https://doi.org/10.46381/reic.v16i0.195

www.criminologia.net

ISSN: 1696-9219 
reglas sobre prescripción aplicables a los correspondientes delitos. Frecuentemente, tanto desde el apoyo informal (familia, amigos) como del formal (policías, abogados, psicólogos, psiquiatras) se toma el control de las decisiones y los procedimientos que se han de seguir, sin considerar a la víctima. Así, el análisis de la información proporcionada por las propias víctimas resulta de gran importancia ya que amplía el conocimiento victimológico sobre este colectivo en nuestro país. Además, proporciona las bases para sugerir cambios en la respuesta jurídica que se les da, considerando que actualmente muchas víctimas afirman no sentirse satisfechas con el tiempo, las medidas y las sentencias que comporta el proceso judicial. Por tanto, los principales objetivos del presente trabajo son: a) conocer el proceso que ha llevado a cabo un grupo de víctimas adultas de abuso sexual infantil respecto a la revelación y la denuncia de los hechos en la infancia y la edad adulta; b) identificar los facilitadores e inhibidores de estas experiencias; c) saber la respuesta de quienes recibieron la revelación o la denuncia; y d) explorar las opiniones y propuestas de las víctimas respecto de la prescripción actual del delito de abuso sexual a menores.

Siguiendo los resultados de estudios anteriores se hipotetiza que a) la mayoría de víctimas de abusos sexuales no habrá revelado los hechos durante la infancia, sino en la edad adulta (Ahrens et al., 2010); b) la respuesta mayoritaria del entorno de la víctima vendrá marcada por la falta de apoyo, la culpabilización y la incredulidad (Mendelsohn \& Sewell, 2004), tanto en la infancia como en la adultez; c) la mayoría de víctimas de abuso sexual infantil no habrá denunciado los hechos (Ullman, 2002); d) los motivos para no denunciar estarán marcados por el miedo y la desconfianza ante el sistema de justicia (Tamarit et al., 2015); e) la mayoría de víctimas de abuso sexual infantil defenderán cambios en el tiempo de prescripción del delito de abusos sexuales infantiles, en la línea de alargar el tiempo para realizar la denuncia. 


\section{Método}

\subsection{Muestra}

La muestra está formada por 15 adultos, con un rango de edad que oscila entre los 20 y 55 años $(M=34,6 ; \mathrm{DT}=10,7)$, víctimas de abuso sexual antes de los 18 años de edad, usuarios de un centro especializado en la atención a víctimas de esta experiencia. El 80\% de los participantes son mujeres.

\subsection{Instrumentos}

Se aplicó un cuestionario ad hoc que recoge datos sociodemográficos de la víctima (i.e., sexo, edad, fecha y lugar de nacimiento, tiempo que llevan en proceso terapéutico) y de los abusos experimentados (i.e., sexo y edad del victimario, relación de la víctima con el victimario, tipo de abuso -con o sin contacto físico-, edad de inicio y de finalización de los abusos). También se elaboró un guión de entrevista semiestructurada, con preguntas respecto a: a) el silencio que rodea los abusos sexuales en la infancia (e.g., tiempo que han tardado en explicar el abuso a alguien comparando la edad de inicio del abuso con el momento de la explicación, si creen que existía dependencia respecto del abusador y si ésta era de tipo social, económica, emocional o de cualquier otro tipo); b) la reacción social hacia los abusos (e.g., qué reacción recibieron al explicar los abusos, de quién, si les sirvió de ayuda,); c) la denuncia de los hechos (e.g., si han denunciado, qué respuestas recibieron al denunciar o por qué escogieron no denunciar, si les sirvió de ayuda) y d) la prescripción del delito (e.g., qué opinan de la prescripción, qué necesitarían del sistema policial y de justicia).

\subsection{Procedimiento}

Se obtuvo la aprobación por parte de la Comisión de Bioética (IRB00003099) para la realización del estudio. También se solicitó el consentimiento informado por escrito a la persona objeto de estudio, conforme aceptaba participar en la investigación y se le explicaron

Revista Española de Investigación Criminológica

Artículo 12, Número 16 (2018)

https://doi.org/10.46381/reic.v16i0.195

www.criminologia.net

ISSN: 1696-9219 
brevemente los objetivos de la misma y la remuneración que recibiría para compensar su desplazamiento el día de la evaluación (20€). En todo momento se respetó el derecho a la confidencialidad, cumpliendo la legislación nacional vigente sobre protección de datos. Se realizó una sesión formativa con el equipo de terapeutas del centro participante en relación a las bases teóricas del estudio, las instrucciones y la forma de conducir las entrevistas y recoger la información. Dos terapeutas del centro aplicaron el instrumento de recogida de datos. Las entrevistas fueron grabadas y posteriormente codificadas en formato electrónico.

\subsection{Análisis}

Se han seguido los principios establecidos por Mayring (2014) respecto al análisis cualitativo de información. Se ha codificado la información obtenida a través de las entrevistas, categorizando las respuestas. Las variables cualitativas en las que se ha focalizado el análisis han sido: a) relativas a la comunicación de los abusos antes y después de los 18 años (e.g., a quién se han comunicado si se ha hecho, la reacción del receptor de esta revelación, y la valoración subjetiva de la víctima de dicha reacción, así como los motivos para no comunicarlo) y b) relativas a la denuncia de los abusos antes y después de los 18 años (e.g., quién interpuso la denuncia y la valoración subjetiva de la víctima de dicha experiencia) y c) la opinión de las víctimas sobre la prescripción del delito. En las preguntas de respuesta abierta se han agrupado los datos por temáticas, como, por ejemplo, las reacciones a la revelación, tanto en la infancia como en la adultez, se han clasificado en negativas (e.g., culpabilidad, incredulidad), positivas (e.g., de apoyo, cariño) o confusas (e.g., pasivas) según la descripción de las víctimas. Se han ilustrado estas categorías a través de fragmentos textuales de los testimonios. Se presentan también datos cuantitativos en forma de frecuencias, porcentajes y otros estadísticos descriptivos multivariantes.

\section{Resultados}

La media de edad del inicio del abuso es de 7 años $(\mathrm{DT}=2,2)$ y la finalización de 11,6 años $(\mathrm{DT}=3,7)$. La duración de los abusos oscila entre 1 y 11 años $(\mathrm{M}=4.33$ años; $\mathrm{DT}=3.6)$. El tipo

\section{Revista Española de Investigación Criminológica}

Artículo 12, Número 16 (2018)

https://doi.org/10.46381/reic.v16i0.195

www.criminologia.net

ISSN: 1696-9219 
de abuso más frecuente es "con contacto físico sin penetración" ( $\mathrm{N}=9,60 \%)$. En la Tabla 1 se resumen las características de las víctimas, de la victimización y del victimario.

\section{Tabla 1.}

Características de la víctima, el abusador y el abuso

\begin{tabular}{|c|c|c|c|c|c|c|}
\hline \multirow{2}{*}{ Variable } & \multirow{2}{*}{$M$} & \multirow{2}{*}{$D T$} & \multicolumn{2}{|c|}{ Rango } & & \\
\hline & & & Mín. & Máx. & & \\
\hline Edad actual de la víctima & 34.6 & 10.7 & 20 & 55 & & \\
\hline $\begin{array}{l}\text { Edad de la víctima al inicio del } \\
\text { abuso }\end{array}$ & 7.0 & 2.2 & 3 & 12 & & \\
\hline $\begin{array}{l}\text { Edad de la víctima al final del } \\
\text { abuso }\end{array}$ & 11.6 & 3.7 & 7 & 18 & & \\
\hline Duración & 4.3 & 3.6 & 1 & 11 & & \\
\hline $\begin{array}{l}\text { Edad del primer abusador al } \\
\text { inicio del abuso }\end{array}$ & 30.5 & 21.7 & 7 & 70 & & \\
\hline & & & & & $N$ & $\%$ \\
\hline \multicolumn{7}{|l|}{ Sexo de la víctima } \\
\hline \multicolumn{5}{|l|}{ Mujer } & 12 & 80.0 \\
\hline \multicolumn{5}{|l|}{ Hombre } & 3 & 20.0 \\
\hline \multicolumn{7}{|l|}{ Tipo de abuso } \\
\hline \multicolumn{5}{|l|}{ Con contacto físico } & 9 & 60.0 \\
\hline \multicolumn{5}{|l|}{ Sin contacto físico } & 0 & 0 \\
\hline \multicolumn{5}{|l|}{ Penetración } & 6 & 40.0 \\
\hline \multicolumn{7}{|l|}{ Número de abusadores } \\
\hline \multicolumn{5}{|l|}{ Uno } & 10 & 66.7 \\
\hline \multicolumn{5}{|l|}{ Dos } & 4 & 26.7 \\
\hline \multicolumn{5}{|l|}{ Tres } & 1 & 6.7 \\
\hline \multicolumn{7}{|l|}{ Relación con el abusador } \\
\hline \multicolumn{5}{|l|}{ Figura paterna } & 3 & 20.0 \\
\hline \multicolumn{5}{|l|}{ Pareja de la madre } & 1 & 3.7 \\
\hline \multicolumn{5}{|l|}{ Hermano/a } & 5 & 33.3 \\
\hline \multicolumn{5}{|l|}{ Tío } & 2 & 13.3 \\
\hline \multicolumn{5}{|l|}{ Abuelo } & 1 & 6.7 \\
\hline \multicolumn{5}{|l|}{ Primo } & 1 & 6.7 \\
\hline \multicolumn{5}{|l|}{ Amigo/a de la familia } & 1 & 6.7 \\
\hline \multicolumn{5}{|l|}{ Otros } & 1 & 6.7 \\
\hline
\end{tabular}




\subsection{Relación de dependencia entre víctima y victimario}

La mayoría de las víctimas confirman la existencia de una relación de dependencia con el abusador $(73.3 \%, \mathrm{~N}=11)$. En la Tabla 2 se resumen las características de estas relaciones de dependencia.

\section{Tabla 2.}

Dependencia del abusador

\begin{tabular}{|c|c|c|}
\hline & $N$ & $\%$ \\
\hline \multicolumn{3}{|l|}{ Dependencia } \\
\hline Sí & 11 & 73.3 \\
\hline No & 4 & 26.6 \\
\hline \multicolumn{3}{|l|}{ Tipo de dependencia* } \\
\hline Emocional & 8 & 72.7 \\
\hline Sin especificar & 3 & 27.3 \\
\hline \multicolumn{3}{|l|}{ Duración* } \\
\hline Aún existe & 4 & 36.6 \\
\hline Muchos años después de que el abuso acabara & 4 & 36.6 \\
\hline Hasta que el abuso terminó & 2 & 18.2 \\
\hline Hasta ser apartado/a del abusador & 1 & 9.0 \\
\hline
\end{tabular}

Al indagar sobre la ruptura de esta dependencia, dos de las entrevistadas (13.3\%) mencionan la psicoterapia como razón: "Que fui a terapia y me di cuenta de lo mala que era esa dependencia para mí. Corté todo sólo de contarlo" (caso 5). Dos explican que la dependencia se rompió una vez que el miembro de la familia ligado con el abusador (a través de un vínculo de pareja o conyugal) se separó: "finalizó cuando hubo una separación conyugal, mi madre lo supo y había maltrato hacia ella también" (caso 6), una lo asoció a la mayoría de edad (caso 8) y uno explicó que lo que definió la ruptura fue enfrentarse al abusador (caso 13). 


\subsection{Comunicación de la victimización antes de los 18 años}

El 60\% de las víctimas (casos 1, 2, 6, 7, 8, 9, 11, 12 y 15) comunicó el abuso a alguien antes de los 18 años de edad. De este grupo, siete escogieron hablar con su madre (casos 2, 6, 7, 9, 11, 12 y 15), una se lo explicó a una pareja de la adolescencia (caso 1) y otra a sus amigas (caso 8). Casi la mitad de los entrevistados ( $\operatorname{casos} 2,6,7,11,12$ y 15) explicaron el abuso a más de una persona antes de los 18 años, siendo los interlocutores más frecuentes otros familiares como los primos, la tía, la pareja del agresor, (casos 2, 6, 11 y 12), los hermanos (casos 2 y 7), una profesora del instituto y la psicóloga de la escuela (caso 15).

Sólo una víctima manifestó que esta explicación le había servido de ayuda. La reacción de su madre cuando le contó el abuso fue: "intentar defenderme, reprender al agresor" (caso 2). El resto de participantes mantiene que haberlo comunicado antes de los 18 años no les sirvió de ayuda. Las reacciones de sus interlocutores fueron de incredulidad: "No daban crédito, credibilidad a lo que estaba contando, de lo fuerte que es. Le creyeron a él" (caso 6, hablando de su madre y su prima) “(...) lo que yo buscaba es que me creyeran y me protegieran, y se acabara ese daño, y no (...). De hecho lo que sentí es que tenía aún más miedo". Otras reacciones fueron de cuestionamiento: "mi madre se puso mal, me preguntó si era verdad (...)" (caso 15) o minimizar el abuso "se rieron, lo minimizaron" (caso 11, sobre su tía y su madre). Algunas víctimas se sintieron culpabilizadas: "acusarme a mí, echarme la culpa" (caso 7, hablando de su madre). Una de las entrevistadas, abusada por su tío, explicó que la reacción de su madre y del entorno familiar fue: "pegarle al abusador y a partir de ahí rechazarle" (caso 12), pero que, de todas maneras, no le ha ayudado. Algunos participantes también mencionan reacciones pasivas como, por ejemplo, de su pareja: "él tenía 16 años, no recuerdo bien su reacción. Supongo que se habrá quedado en shock, tengo una sensación de que fue una reacción "pasiva", como "vale, oído"” (caso 1) o “mis hermanos eran oyentes, nunca se han posicionado" (caso 7).

Revista Española de Investigación Criminológica

Artículo 12, Número 16 (2018)

https://doi.org/10.46381/reic.v16i0.195

www.criminologia.net

ISSN: 1696-9219 


\subsection{Comunicación después de los 18 años}

Seis participantes explicaron el abuso sólo en la adultez (6, casos 3, 4, 5, 10, 13 y 14), mientras que otros seis lo explicaron tanto en la infancia como en la edad adulta $(\mathrm{N}=6$, casos 1, 6, 7, 8, 9 y 12). La agrupación de los datos respecto a la comunicación del abuso está resumida en la Tabla 3 .

\section{Tabla 3.}

Comunicación del abuso

\begin{tabular}{|l|c|c|}
\cline { 2 - 3 } \multicolumn{1}{c|}{} & $\boldsymbol{N}$ & $\mathbf{\%}$ \\
\hline Sólo antes de los 18 años & 3 & 20 \\
\hline Sólo después de los 18 años & 6 & 40 \\
\hline Antes y después de los 18 años & 6 & 40 \\
\hline
\end{tabular}

Aquellos que hablaron del abuso siendo menores y también de mayores escogieron interlocutores muy diversos en cada etapa. Por ejemplo, el caso 1 explicó el abuso a su pareja en la adolescencia y en la adultez, a una conocida que también había sufrido abusos. Los casos 7 (en la infancia lo explicó a sus hermanos) y 12 (durante la infancia lo explicó a su madre), de adultos escogieron explicárselo a su padre. El caso 9 (durante la infancia lo explicó a su madre) después de los 18 años explicó el abuso a otros miembros de la familia. Tres casos (casos 6, 11 y 15) que habían explicado el abuso a su madre antes de los 18 años lo volvieron a hacer siendo mayores de edad. La reacción de la madre antes de la mayoría de edad fue: "no dar crédito" (caso 6), "reírse y minimizarlo" (caso 11) y "cuestionarme" (caso 15). Al volver a abordar el tema, una madre creyó a la víctima (caso 6), otra le preguntó que por qué se había dejado hacer una cosa así (caso 11) y la madre del caso 15 fue a hablar con el abusador y acabó creyendo su versión.

Aquellos que sólo explicaron el abuso de adultos, lo hicieron a un psiquiatra (caso 14), a amigos (casos 4, 10, 13 y 14), a hermanos (casos 8 y 12) y a su pareja (casos 3,9 y 12). Algunos casos se mencionan en varias ocasiones porque revelaron los abusos a más de una persona durante la adultez (e.g., caso 12, lo explicó a su padre, hermanos y pareja). 
El $61.5 \%(\mathrm{~N}=8$; $\operatorname{casos} 1,4,6,7,10,12,13$ y 14$)$ dijo que le había servido de ayuda explicar el abuso después de los 18 años. Cinco participantes (casos 3, 5, 9, 11 y 15) dijeron que no. Los participantes que sintieron que no les había ayudado describieron las reacciones de sus interlocutores como pasivas, por ejemplo: "no me hizo ni caso", "no exteriorizó ninguna reacción" (caso 3 y 5 respectivamente, hablando de sus parejas). Algunos participantes dijeron que no les habían creído: "hablaron con el abusador y él lo negó” (caso 15, hablando de su familia) o que los culpabilizaron: “¿por qué te has dejado hacer eso?” (caso 11, hablando de su madre). También recibieron reacciones evasivas: "los profesionales no querían hablar de ello" (caso 9) o "si has estado callada hasta ahora, ¿por qué no has seguido callada?" (caso 11, hablando de su padre). Una víctima dijo que su pareja había utilizado esta revelación para manipularla y que sus amistades le dejaron de hablar (caso 9).

Por otro lado, los participantes que percibieron que comunicar el abuso les había ayudado describieron reacciones muy diversas. Algunas fueron positivas: "me escuchó y luego me contó su historia, que también incluía abusos" (caso 1, hablando de otra víctima), "me comprendió" (caso 13, en referencia a su madre), "protección hacia mí" (caso 12, hablando de su pareja), "mi padre me abrazó y me entendió" (caso 12). El caso 7, que había sufrido abusos por parte de su hermano, explicó que le ayudó contárselo a su padre: "No le desamparó luego porqué él era drogadicto, porque lo cuidó y lo llevó a los médicos, pero me dio el lugar que yo me merecía. Me cuidó y protegió. Evitaba que estuviéramos juntos”. Otras reacciones fueron clasificadas como negativas: "angustia, impotencia" (caso 4, hablando de su madre y una amiga), "compasión o pena" (caso 6, hablando de su madre), "mi madre no ha preguntado más y yo no le he dejado preguntar" (caso 14). Cabe recordar que, de todas formas, los participantes sintieron que explicarlo les había servido. Finalmente, hubo reacciones confusas: "sorpresa" (caso 4, hablando de la madre y de una amiga), "al principio no entendían, fue raro" (caso 14, en referencia a sus amigas). Algunas reacciones fueron ambivalentes: "que por qué no había denunciado o no denunciaba, la indignó no haberlo sabido antes, y me animó a denunciar" (caso 6, hablando de su amiga), "a mi padre se lo conté por teléfono, vino a buscarme, y su reacción fue "por qué no me lo has contado antes" 
(...) Es como que quería decir que hubiera reaccionado, hubiera hecho algo, lo hubiéramos cambiado" (caso 7)

\subsection{Denuncia de la victimización antes de los 18 años}

Sólo el caso 2 denunció los hechos antes de los 18 años. La persona que interpuso la denuncia en nombre de la víctima fue la madre, cuando la víctima tenía 13 años, 6 años después de que acabaran los abusos. El motivo por el cual se realizó la denuncia responde a la necesidad de buscar justicia por parte de la víctima: "Creía que se tenía que hacer justicia. Que al menos él recibiría algo de lo que se merecía”. En relación a las consecuencias de interponer la denuncia, la víctima manifiesta que al principio fue duro, pero que con respecto al entorno de su madre se sintió "más aliviada".

Respecto a los motivos por los cuales no se denunciaron los hechos antes de los 18 años, los casos 5, 6, 11, 14 y 15 manifiestan que no lo hicieron por miedo a las posibles consecuencias que podía tener la denuncia sobre ellos mismos, sobre su entorno familiar y social. Los casos 3, 7, 9 y 12 indican que el motivo de la no denuncia se corresponde a una falta de apoyo por parte de la familia, excepto en el caso 9, donde la falta de apoyo fue por parte de un médico. Los casos 4 y 10 no denunciaron porque su entorno no conocía los hechos. El caso 1 manifiesta que no denunció porque desconocía que aquellos hechos podían constituir un delito, mientras que el caso 8 no denunció porque su victimario era Guardia Civil. La dependencia con el victimario fue el motivo de no denuncia para los casos 6 y 13.

\subsection{Denuncia después de los 18 años}

Dos casos denunciaron los hechos después de los 18 años. En ambos denunció la propia víctima. Respecto a los motivos de la denuncia, un caso manifestó que: "no quería que otra persona pasara lo mismo que estoy pasando yo" (caso 4), mientras que el caso 6 denunció gracias al apoyo terapéutico que recibía. La edad en el momento de la denuncia fue de 25 y 34 años, respectivamente. Si se contrastan estas edades con las edades en las cuales tuvieron lugar los abusos, entre la edad de finalización del abuso y la edad en la cual se interpuso la denuncia transcurrieron 18 y 17 años, respectivamente.

Revista Española de Investigación Criminológica

Artículo 12, Número 16 (2018)

https://doi.org/10.46381/reic.v16i0.195

www.criminologia.net

ISSN: 1696-9219 
Respecto a las valoraciones sobre los efectos psicológicos que tuvo el proceso judicial, ambas víctimas manifiestan que fue duro: "Negativo. Me juzgaban más a mí que al delincuente" (caso 4) y "Para mí ha sido muy duro, pero también muy positivo y gratificante... de alguna forma me ayuda a seguir para adelante... sentirme más libre y digna como persona. Respirar menos miedo. Necesitaba que se me escuchara y se supiera" (caso 6). Ambos casos manifiestan que las consecuencias de haber denunciado son positivas a pesar del malestar causado durante el proceso.

En relación a los motivos para no interponer la denuncia después de los 18 años, los casos 3, 8, 9 y 10 manifiestan la vergüenza como motivo principal. La muerte del victimario fue motivo para no denunciar los hechos en los casos 7 y 11 . Tres de los participantes (casos 1, 13 y 14) indicaron que el miedo a las consecuencias de la denuncia los hizo no poner en conocimiento de las autoridades los hechos delictivos (el caso 14 indica el miedo a ser etiquetado como víctima). El caso 1 explicó que tenía: "miedo a la ruptura familiar. Mi madre tiene que elegir entre dos hijos. Miedo que legalmente pudieran culpar a mi madre. Además, no me van a hacer caso, no me van a creer. Y no va a servir de nada, soy consciente de la prescripción”. El caso 5 indica que no quiere denunciar porque cree que entrar en el circuito judicial comportaría más problemas que beneficios, mientras que el caso 12 alude a la falta de apoyo por parte del entorno familiar. Finalmente, el caso 15 indica que el motivo de la no denuncia se corresponde con su desconocimiento al respecto (pensaba que ya habían prescrito los hechos delictivos). La víctima comenta que quiere denunciar los hechos, ahora que sabe que está a tiempo.

\subsection{Opinión sobre la prescripción del delito de abusos sexuales a menores}

El 100\% de la muestra indica que el delito de abuso sexual a menores no debería prescribir y manifiesta no encontrarse de acuerdo con el tiempo establecido en el articulado legal vigente. Los motivos para mantener esta posición se muestran en la Tabla 4. 
Pereda, Gómez-Martín, Greco, Hombrado \& Segura

\section{Tabla 4.}

Motivos para la no prescripción del delito

\begin{tabular}{|l|c|c|}
\cline { 2 - 3 } \multicolumn{1}{c|}{} & $\boldsymbol{N}$ & $\mathbf{\%}$ \\
\hline Tiempo necesario para una víctima hasta sentirse segura & 5 & 31.2 \\
\hline Necesidad de hacer justicia & 2 & 12.5 \\
\hline Creencia de que los menores no pueden denunciar como los adultos & 2 & 12.5 \\
\hline Alto coste psicológico & 7 & 43.7 \\
\hline
\end{tabular}

Nota. Los totales superan los 15 casos porque una misma víctima puede haber dado más de un motivo.

Estos datos se ilustran con las siguientes afirmaciones: "Las consecuencias del abuso no prescriben. Y, además, las penas son muy "blandas", 2, 3 años en cárcel o 3.000 euros. Ya me lo he gastado en terapia eso... No denunciaría por el dinero, pero si eso es lo que vale abusar de tu hermanastra..." (caso 1); "Porque el daño que se le hace a la persona lo lleva consigo toda la vida, entonces ¿por qué va a prescribir? ... y más cuando eres menor, si no tienes un adulto que te acompañe no lo puedes hacer por ti solo, si cuesta decirlo a alguien, ¿cómo vas a ir ante un juez?” (caso 7); "Porque a lo mejor yo ahora no quiero, pero más adelante sí, ahora no tengo fuerzas ni psicológicas... pero a lo mejor si pasan un par de años, puede que me sienta mejor conmigo misma y quiera denunciar" (caso 14).

\subsection{Opinión sobre posibles propuestas de modificación legal}

La mayoría de participantes $(\mathrm{N}=10)$ se manifiesta satisfecha ante una posible ampliación del tiempo de prescripción del delito de abuso sexual. Los 5 casos restantes indican que la ampliación del tiempo de prescripción no es una buena modificación: "porque es un tema muy personal y cada uno tiene sus tiempos" (caso 2) y "porque hay personas que hablan con 80 años, no debemos dejar un límite de edad" (caso 5).

Cinco de los 15 casos (casos 1, 2, 6, 9 y 13) proponen que se tendrían que endurecer las penas de este delito. En 3 casos (casos 4, 7 y 12) también se indica que se tendría que escuchar y creer más a las víctimas en los procesos judiciales y que se tendría que evitar juzgar su discurso. Tres participantes (casos 5, 11 y 14) insisten en la necesidad de que los delitos no puedan prescribir como propuesta (uno de ellos manifiesta que no cree en la

\section{Revista Española de Investigación Criminológica}


justicia). El caso 3 indica que se tendría que apostar más por la prevención e información en la sociedad para evitar estos delitos. Los casos 10 y 15 no aportan propuestas adicionales.

\section{Discusión}

Los abusos sexuales descritos por las víctimas del presente estudio siguen los resultados obtenidos en trabajos anteriores con estudiantes universitarios de la misma zona geográfica que, generalmente, describen una edad de inicio prepuberal, conductas crónicas y abusos con contacto físico en la mayoría de casos (Benavente et al., 2016). Sin embargo, el porcentaje de abusos con penetración y de figuras paternas y familiares es más alto, lo que podría deberse al origen clínico de la muestra. Otro punto importante y preocupante es el grupo de abusadores de edad similar a la de la víctima, también mencionada en estudios previos (López, 1994; Pereda \& Forns, 2007). A nivel preventivo, se hace necesario analizar los factores que influyen en que un menor de edad abuse sexualmente de otro menor, factores que parecen no haber cambiado en los últimos años. Como señala el estudio de McKikkin, Humphreys y Hamilton (2017), hablar con los jóvenes de educación sexual, tratar las propias experiencias de victimización, si las hay, y ayudarlos a entender qué es la pornografía y cómo gestionar las sensaciones que puede producirles serían tres aspectos que ayudarían a prevenir situaciones abusivas.

La dependencia emocional entre víctima y victimario, uno de los motivos principales en la no notificación de los casos de abuso sexual (Payne \& Hansen, 2002), está presente en la gran mayoría de la muestra, si bien sólo dos de las víctimas la mencionan como motivo para no haber denunciado el hecho. Se refuerza la idea de que la dependencia impide la revelación ya que la víctima puede sentir que está traicionando al abusador, especialmente cuando es la figura paterna, pero no necesariamente tiene por qué ser un motivo para no denunciar una vez revelada la experiencia. En el presente estudio, los participantes hacen mención a la ruptura de esta dependencia como un factor positivo para sí mismos, pese a no manifestar una opinión favorable en relación a la denuncia. Es importante considerar que la mitad de las víctimas manifiestan que la relación de dependencia emocional con el abusador todavía perdura.

\section{Revista Española de Investigación Criminológica}

Artículo 12, Número 16 (2018)

https://doi.org/10.46381/reic.v16i0.195

www.criminologia.net

ISSN: 1696-9219 
Respecto a la primera hipótesis del trabajo, un resultado relevante e inesperado es que la mayoría de las víctimas manifiestan haber comunicado los hechos durante la infancia a alguien cercano, principalmente a su madre, pero también posteriormente, en la edad adulta, a otras personas. Este resultado parece indicar que la revelación del abuso no es un suceso único y puntual, sino un proceso en el cual la víctima puede llegar a hablar con diversas personas y recibir diferentes respuestas (Alaggia, 2004); la mayoría, como demuestran los resultados, de incredulidad y falta de apoyo.

Es interesante ver cómo revelar los hechos durante la infancia no supone una ayuda para la mayoría de las víctimas, si bien sí lo es revelar los hechos en la edad adulta. Diversas conclusiones derivan de estos resultados. En primer lugar, desafortunadamente, es posible que los adultos no estén preparados para hacer frente a una revelación de abuso sexual por parte de un hijo o de un menor del entorno cercano, especialmente cuando el abusador también se encuentra dentro del ámbito familiar. La falta de sensibilización y reconocimiento de la existencia del abuso sexual en la población de nuestro país son alertados desde hace años por instituciones de atención a víctimas, como la Fundación RANA o la Fundación Vicki Bernadet. En muchas ocasiones, incluso los profesionales llegan a dudar y se posicionan de forma defensiva cuando se les presentan los resultados de los múltiples estudios llevados a cabo en nuestro país que así lo confirman (Pereda, 2016), lo cual también se refleja en uno de los testimonios recogidos en el presente estudio. También es posible que a los niños y niñas les cueste detectar, durante la infancia, aquella persona que los protegería y apoyaría frente a los abusos. Pareciera que las víctimas tienen mayores herramientas para identificar este tipo de personas en la edad adulta, lo cual puede redundar en el hecho de informar de una mayor satisfacción con el apoyo recibido en edades más tardías y que vendría derivado de haber sabido detectar una persona idónea para la revelación. Estudios previos con muestras de menores víctimas de abuso sexual infantil en Alemania constatan que la madre de la víctima es el principal receptor de la revelación cuando la víctima es menor (Münzer et al., 2014) y, por tanto, debería sensibilizarse a este colectivo respecto a su papel ante estos casos. 
En relación a la segunda hipótesis, respecto a las reacciones recibidas por las personas a quienes las víctimas explicaron los hechos, éstas son diversas y se encuentran tanto respuestas positivas y de apoyo, especialmente en la edad adulta, como negativas de incredulidad y culpa, sobre todo durante la infancia, y respuestas ambivalentes. Sorprende que las víctimas afirmen que sintieron menos apoyo durante la infancia que en la edad adulta, contradiciendo otros estudios (Münzer et al., 2014). Es posible que las características clínicas de la muestra y la aproximación cualitativa de este trabajo, nuevamente, estén incidiendo en estos resultados. O que esta diferencia se deba a aspectos culturales. Recibir el apoyo y la aceptación de la persona receptora de la revelación durante la infancia, especialmente si es la madre de la víctima, se ha relacionado con un mejor pronóstico y recuperación emocional (Zajac, Ralston \& Smith, 2015), lo cual resulta relevante ya que en los resultados de este análisis este apoyo parece ausente o no percibido por las víctimas. El apoyo de la madre de la víctima también supone una menor cantidad de retractaciones una vez que el abuso es denunciado y una declaración más completa (Lippert, Cross, Jones, \& Walsh, 2009), resultados de gran relevancia para el ámbito judicial. Nuevamente, los resultados indican que trabajar con el colectivo de madres es fundamental. Respecto a las reacciones ambivalentes o confusas, que no muestran ni un rechazo ni un apoyo claros a la víctima, si bien pueden ser entendidas como bienintencionadas, pueden acabar generando un gran malestar y propiciar el desarrollo de síntomas psicopatológicos (Pereda \& Sicilia, 2017). Es evidente que la experiencia de abuso sexual infantil desborda los recursos de las víctimas y de su entorno y es necesario que los profesionales valoren siempre poder intervenir con todos los implicados, desde una perspectiva familiar y sistémica. En este sentido, se sugiere aumentar las intervenciones sobre el impacto que la revelación o el descubrimiento del abuso sexual causa en los progenitores no agresores de la víctima, como destaca Davies (1995).

Durante la infancia, y en línea con el estudio clásico de Palmer y colaboradores (1999), y parcialmente con el trabajo de Tamarit et al. (2015), la mayoría de víctimas no denunciaron los hechos por miedo a las consecuencias de la denuncia sobre sí mismas, pero también sobre su entorno familiar y social, tal y como se hipotetizaba. 
Un porcentaje importante de las víctimas aluden a la falta de apoyo por parte de su entorno, que en un caso supone un profesional, y que vuelve a alertarnos de la enorme responsabilidad que tiene la persona que recibe la revelación de los abusos en el proceso de notificación y denuncia. En la edad adulta, sólo dos víctimas han denunciado los hechos, habiendo transcurrido cerca de 20 años entre la edad de inicio de los abusos y el momento de la denuncia, corroborando la tercera hipótesis del estudio relativa al escaso porcentaje de denuncia. El tiempo transcurrido entre la victimización y la denuncia es un dato relevante para una posible revisión de los criterios de prescripción de los delitos sexuales contra la infancia y muestra que la víctima requiere de un tiempo significativo para sentirse preparada para denunciar. Al mismo tiempo, es un resultado muy esperanzador que las víctimas que han denunciado los hechos sientan que las consecuencias, tras un cierto malestar inicial, son positivas. Aquellas víctimas que no han denunciado los hechos manifiestan el miedo a las consecuencias derivadas de la denuncia y la vergüenza como motivos principales para no haberlo hecho. Cabe recordar que para una de las víctimas la prescripción fue el motivo por el cual decidió no denunciar, mostrando el efecto que puede tener una potencial modificación de esta legislación.

Respecto a los plazos de prescripción, y de acuerdo con la última hipótesis del estudio, todas las víctimas consideran que se han de modificar y que los abusos no deberían prescribir ya que no prescriben las consecuencias ni el malestar que se derivan de ellos. Sobre la posible ampliación de los plazos de prescripción, la mayoría de víctimas lo consideran un avance, pero ninguna de ellas la considera la solución definitiva, dado que opinan que establecer unos marcadores temporales determinados no permitirá incluir a todas las víctimas, ya que no hay un tiempo estándar ni unas variables que nos permitan estimar a qué edad una víctima decidirá, o no, interponer una denuncia.

Desde una perspectiva jurídica, debe recordarse, no obstante, que una ampliación desmesurada de los plazos de prescripción del delito, también en los casos que nos ocupan, produciría consecuencias difícilmente asumibles como atentar contra el principio de proporcionalidad, al extenderse la regla de la imprescriptibilidad a hechos delictivos de gravedad y alcance muy dispar (Gómez Martín, 2016).

\section{Revista Española de Investigación Criminológica}


Si bien el discurso punitivo se encuentra presente en un porcentaje importante de víctimas, otra parte de la muestra con el mismo porcentaje manifiesta un discurso restaurativo que pide que se escuche más a las víctimas durante el proceso judicial o invertir más en programas de prevención y sensibilización sociales. Es importante ser conscientes que la variabilidad en el estado emocional de los participantes y la no superación de los abusos pueden hallarse en la base de estas respuestas, ya que la mayoría de víctimas que superan la victimización no mantienen una actitud punitiva, sino reparadora demandando buen trato, respeto, exactitud en el proceso, imparcialidad y justicia según el metanálisis de Laxminarayan, Bosmans, Porter y Sosa (2013).

\subsection{Puntos fuertes y limitaciones}

El presente estudio destaca por su enfoque ya que combina aspectos sociales con factores judiciales y analiza su posible conexión. En este sentido, si bien existe evidencia internacional sobre la reacción a la revelación del abuso sexual infantil y los motivos que tienen las víctimas para no revelar y/o denunciar, la posibilidad de que exista una relación entre la vivencia subjetiva de la víctima y la posterior denuncia está poco estudiada en nuestro país.

No obstante, el trabajo no está exento de limitaciones. Un punto fundamental a señalar es el tamaño de la muestra, puesto que, al buscar la profundidad del conocimiento de carácter cualitativo, las conclusiones extraídas no pueden considerarse generalizables. Asimismo, hubiera sido interesante contar con otros datos, como la edad de la víctima al comunicar el abuso a alguien por primera vez o mayor información sobre cómo influye la dependencia en la decisión de revelar. Futuros estudios podrían abordar estas cuestiones desde un diseño cuantitativo y recoger también esta información, a fin de investigar si los resultados obtenidos en este estudio son reproducibles en muestras más grandes y analizar más profundamente algunas variables como, por ejemplo, si existe algún tipo de patrón o relación entre la edad de inicio y la comunicación de los abusos por primera vez o cómo influyen las diversas formas de dependencia entre víctima y victimario en los procesos de revelación. 


\section{Conclusión}

Son múltiples las barreras personales y sociales que llevan a la víctima de abusos sexuales a guardar silencio durante años y a no valorar la revelación de los hechos como una opción de ayuda. Asimismo, la proporción de casos que se denuncian sigue siendo baja y con una valoración del proceso por parte de las víctimas más bien negativa. Es necesaria una mayor sensibilización social para que todos los colectivos que suelen recibir las revelaciones, particularmente el de las madres, sea consciente de los potenciales efectos de su reacción y de la necesidad de brindar apoyo a las víctimas, tanto en la infancia como en la adultez. A su vez, el sistema de justicia debe responder a esta realidad planteando cambios en lo que, hasta el momento, no ha sido la respuesta más adecuada para un problema altamente complejo y ante el que el período actual de prescripción es, claramente, insuficiente si lo que se pretende es potenciar la denuncia de estos casos y ofrecer una respuesta justa a las víctimas de estos delitos. 


\section{Referencias}

Ahrens, C., Stansell, J., \& Jennings, A. (2010). To tell or not to tell: The impact of disclosure on sexual assault survivors' recovery. Violence and Victims, 25(5), 631-648. doi:10.1891/0886-6708.25.5.631

Alaggia, R. (2004). Many ways of telling: Expanding conceptualizations of child sexual abuse disclosure. Child Abuse \& Neglect, 28, 1213-1227. doi:10.1016/j.chiabu.2004.03.016

Alaggia, R. (2010). An ecological analysis of child sexual abuse disclosure: Considerations for child and adolescent mental health. Journal of the Canadian Academy of Child and Adolescent Psychiatry, 19(1), 32-39.

Alaggia, R., \& Kirshenbaum, S. (2005). Speaking the unspeakable: Exploring the impact of family dynamics on child sexual abuse disclosures. Families in Society, 86(2), 227234. doi:10.1606/1044-3894.2457

Baca, E. (2003). La actitud ante la víctima: Reacciones personales, sociales y profesionales. En E. Baca y M.L. Cabanas (Eds.). Las víctimas de la violencia (pp. 239-273). Madrid: Triacastela.

Benavente, B., Casado, S., Orte, C., \& Ballester, L1. (2016). Prevalencia del abuso sexual en la infancia. Un estudio en estudiantes universitarios. Barcelona: Octaedro.

Davies, M.G. (1995). Parental distress and ability to cope following disclosure of extrafamilial sexual abuse. Child Abuse \& Neglect, 19(4), 399-408. doi:10.1016/01452134(95)00010-6

Draucker, C.B., Martsolf, D.M., Roller, C., Knapik, G., Ross, R., \& Warner, A. (2011). Healing from childhood sexual abuse: A theoretical model. Journal of Child Sexual Abuse, 20(4), 435-466. doi:10.1080/10538712.2011.588188

Fisher, B.S., Daigle, L.E., Cullen, F.T., \& Turner, M.G. (2003). Reporting sexual victimization to the police. Criminal Justice and Behavior, 30(1), 6-38. doi:10.1177/0093854802239161

Gómez Martín, V. (2016). La prescripción del delito. Una aproximación a cinco cuestiones aplicativas. Montevideo - Buenos Aires: B de F.

Laxminarayan, M., Bosmans, M., Porter, R., \& Sosa, L. (2013). Victim satisfaction with criminal justice: A systematic review. Victims \& Offenders: An International Journal of Evidence-based Research, Policy, and Practice, 8(2), 119-147. doi:10.1080/15564886.2012.763198

Lievore, D. (2003). Non-reporting and hidden recording of sexual assault: An international literature review. Canberra: Common Wealth of Australia.

Revista Española de Investigación Criminológica

Artículo 12, Número 16 (2018)

https://doi.org/10.46381/reic.v16i0.195

www.criminologia.net

ISSN: 1696-9219 
Lippert, T., Cross, T.P., Jones, L.M., \& Walsh, W.A. (2009). Telling interviewers about sexual abuse: Predictors of child disclosure at forensic interviews. Child Maltreatment, 14(4), 100-113. doi:10.1177/1077559508318398

López, F. (1994). Los abusos sexuales de menores. Lo que recuerdan los adultos. Madrid: Ministerio de Asuntos Sociales.

Mayring P. (2014). Qualitative content analysis: Theoretical foundation, basic procedures and software solution. Austria: Klagenfurt.

McKiggin, G., Humphreys, C. \& Hamilton, B. (2017). "Talking about child sexual abuse would have helped me": Young people who sexually abused reflect on preventing harmful sexual behavior. Child Abuse \& Neglect, 70, 210-221. doi:10.1016/j.chiabu.2017.06.017

Mendelsohn, M., \& Sewell, K.W. (2004). Social attitudes toward traumatized men and women: A vignette study. Journal of Traumatic Stress, 17(2), 103-111. doi:10.1023/B:JOTS.0000022616.03662.2f

Münzer, A., Fegert, J.M., Ganser, H.G., Loos, S., Witt, A., \& Goldbeck, L. (2014). Please tell! Barriers to disclosing sexual victimization and subsequent social support perceived by children and adolescents. Journal of Interpersonal Violence, 1-23. doi:10.1177/0886260514555371

Palmer, S.E., Brown, R.A., Rae-Grant, N.I., \& Loughlin, M.J. (1999). Responding to children's disclosure of familial abuse: What survivors tell us. Child Welfare, 78(2), 259-282.

Payne, M.L., \& Hansen, D.J. (2002). Factors influencing children to self-disclose sexual abuse. Clinical Psychology Review, 22(2), 271-295. doi:10.1016/S02727358(01)00091-5

Pereda, N. (2016). ¿Uno de cada cinco?: Victimización sexual infantil en España. Papeles del Psicólogo, 37(2), 3-13.

Pereda, N., Abad, J., \& Guilera, G. (2016). Lifetime prevalence and characteristics of child sexual victimization in a community sample of Spanish adolescents. Journal of Child Sexual Abuse, 25(2), 142-158. doi:10.1080/10538712.2016.1123791

Pereda, N., \& Forns, M. (2007). Prevalencia y características del abuso sexual infantil en estudiantes universitarios españoles. Child Abuse \& Neglect, 31, 417-426. doi:10.1016/j.chiabu.2006.08.010

Pereda, N., \& Sicilia, L. (2017). Reacciones sociales ante la revelación de abuso sexual infantil y malestar psicológico en mujeres víctimas. Psychosocial Intervention, 26(3), 131-138. doi:10.1016/j.psi.2017.02.002

Priebe G., \& Svedin, C.G. (2008). Child sexual abuse is largely hidden from the adult society. An epidemiological study of adolescents' disclosures. Child Abuse \& Neglect, 32, 1095-1108. doi:10.1016/j.chiabu.2008.04.001.

Revista Española de Investigación Criminológica

Artículo 12, Número 16 (2018)

https://doi.org/10.46381/reic.v16i0.195

www.criminologia.net

ISSN: 1696-9219 
Smyth, J.M., Pennebaker, J.W., \& Arigo, D. (2012). What are the health effects of disclosure? En A. Baum, T.A. Revenson \& J.E. Singer (Eds). Handbook of health psychology (2nd edition, pp. 175-191). New York: Psychology Press.

Sorsoli, L., Kia-Keating, M., \& Grossman, F.K. (2008). I keep that hush-hush: Male survivors of sexual abuse and the challenges of disclosure. Journal of Counseling Psychology, 55, 333-345. doi:10.1037/0022-0167.55.3.333

Spiegel, D., Loewenstein, R.J., Lewis-Fernández, R., Sar, V., Simeon, D., Vermetten, E., Cardeña, E., \& Dell, P.F. (2011). Dissociative disorders in DSM-5. Depression and Anxiety, 28, 824-852. doi:10.1002/da.20874

Stroud, D.D. (1999). Familial support as perceived by adult victims of childhood sexual abuse. Sexual Abuse: A Journal of Research and Treatment, 11(2), 159-175. doi:10.1007/BF02658845

Tamarit, J.M., Abad, J., \& Hernández-Hidalgo, P. (2015). Las víctimas de abuso sexual infantil ante el sistema de justicia penal: Estudio sobre sus actitudes, necesidades y experiencia. Revista de Victimología, 2, 27-54. doi:10.12827/RVJV.2.02

Tener, D., \& Murphy, S.B. (2015). Adult disclosure of child sexual abuse: A literature review. Trauma, Violence, \& Abuse, 16(4), 391-400. doi:10.1177/1524838014537906

Ullman, S.E. (1999). Social support and recovery from sexual assault: A review. Aggression and Violent Behavior, 4, 343-358. doi:10.1016/S1359-1789(98)00006-8

Ullman, S.E. (2002). Social reactions to child sexual abuse disclosures: A critical review. Journal of Child Sexual Abuse, 12(1), 89-121. doi:10.1300/J070v12n01_05

Zajac, K., Ralston, M.E., \& Smith, D.W. (2015). Maternal support following childhood sexual abuse: Associations with children's adjustment post-disclosure and at 9-month follow-up. Child Abuse \& Neglect, 44, 66-75. doi:10.1016/j.chiabu.2015.02.011

\section{Agradecimientos}

Los autores agradecen al Centro de Estudios Jurídicos y Formación Especializada, institución adscrito al Departamento de Justicia de la Generalitat de Catalunya, su apoyo económico en la realización de este estudio.

\section{Biografía de los autores}

Noemí Pereda es doctora en psicología clínica y de la salud, profesora titular de victimología en la Universitat de Barcelona e investigadora ICREA Academia. Se ha especializado en la temática de la victimología del desarrollo. Es asesora de la Oficina Regional Europea de la OMS en el estudio de la violencia infantojuvenil en España y asesora experta de la organización Save the Children. Colabora con el Crimes against Children Research Center (University of New Hampshire, EUA) y el Institute of Criminology (University of

\section{Revista Española de Investigación Criminológica}

Artículo 12, Número 16 (2018)

https://doi.org/10.46381/reic.v16i0.195

www.criminologia.net

ISSN: 1696-9219 
Cambridge, Reino Unido). Dirige el Grupo de Investigación en Victimización Infantil y Adolescente (GReVIA) desde su creación.

iD https://orcid.org/0000-0001-5329-9323

Víctor Gómez Martin es doctor en derecho y profesor titular de derecho penal de la Universitat de Barcelona. Acreditado como Catedrático por la Agencia Nacional de Evaluación de la Calidad y Acreditación. Es jefe de los Estudios Criminológicos y de la Seguridad de la Universitat de Barcelona. Ha sido investigador en los institutos de derecho penal, política criminal y criminología de las universidades alemanas de Freiburg, Berlín y Bremen. Ha participado en conferencias y docencia en Alemania (Manhheim, Erlangen), Argentina (Buenos Aires, Mendoza), Chile (Valparaíso), Francia (Lyon), Italia (Modena, Nápoles), Ecuador (Quito), Nicaragua (Managua) y Turquía (Diyarbakir, Ankara).

iD https://orcid.org/0000-0002-3302-6210

Ana Martina Greco es investigadora predoctoral en el Departamento de Psicología Social y Psicología Cuantitativa de la Universitat de Barcelona. Su interés de investigación se centra en el estudio del papel de la educación y sus profesionales en la protección infantil. Su tesis doctoral aborda la prevención, detección e intervención de la victimización infantil y juvenil desde la escuela. Es miembro del Grupo de Investigación en Victimización Infantil y Adolescente (GReVIA) de la Universitat de Barcelona.

iD https://orcid.org/0000-0001-5285-580X

Jaume Hombrado es investigador predoctoral en el Departamento de Derecho Penal y Criminología en la Universitat de Barcelona. Su interés de investigación se centra en el estudio de medidas alternativas para la resolución de conflictos, así como sus efectos en victimarios y víctimas. Su tesis doctoral trata sobre los procesos de justicia restaurativa y su aplicación en el contexto de violencia en la pareja. Es miembro del Grupo de Investigación en Victimización Infantil y Adolescente (GreVIA) de la Universitat de Barcelona.

iD https://orcid.org/0000-0002-6156-8383

Anna Segura es doctora en psicología clínica y de la salud por la Universitat de Barcelona y profesora en la Facultad de Psicología de la Universitat de Vic-Universitat Central de Catalunya (UVic-UCC). Sus áreas de interés incluyen los efectos de la victimización y la polivictimización en niños, niñas y adolescentes en riesgo, la resiliencia y los factores de protección $\mathrm{y}$ ha publicado diversos artículos en esta área. Es miembro del Grupo de Investigación en Victimización Infantil y Adolescente (GReVIA) de la Universitat de Barcelona.

iD https://orcid.org/0000-0002-4655-1858

Revista Española de Investigación Criminológica

Artículo 12, Número 16 (2018)

https://doi.org/10.46381/reic.v16i0.195

www.criminologia.net

ISSN: 1696-9219 